\title{
Analysis and Optimization on Spatial Structure of Tourist Attractions in Ankang
}

\author{
Ma Teng \\ College of Urban and Environmental Sciences \\ Northwest University \\ Xi'an710127, China \\ Wang Xing \\ College of Urban and Environmental Sciences \\ Northwest University \\ Xi’an710127, China
}

\author{
Tang Beipei \\ College of Urban and Environmental Sciences \\ Northwest University \\ Xi'an710127, China \\ Li Julin \\ College of Urban and Environmental Sciences \\ Northwest University \\ Xi'an710127, China
}

\author{
Rui Yang* \\ College of Urban and Environmental Sciences \\ Northwest University \\ Xi'an710127, China
}

\begin{abstract}
Take Ankang as an example, we explore Spatial distribution characteristics, structure and pattern of its class-A tourist attractions and make suggestions on the spatial structure adjustment, basing on mathematical and spatial statistical methods such as coefficient of variation, spatial cluster, nuclear density estimation and Zipf model. The results indicated that: 1 . Spatial clustering character of Ankang class-A tourist attractions is significant and shown prominent "core-edge" spatial structure feature. 2. Tourist attractions are mainly distributed in the Yuehe plain and along the river area of Shi-Zi-Lan, forming two agglomeration centers in the both sides of Fenghuang Mountain and the central city. The pattern was shaped by regional topography features, practice of local tourism development and other factors in common. 3. The key to optimize the spatial structure of Ankang class-A tourist attractions lies in the formation of reasonable tourist attractions system and "One core two corridors three areas" regional tourism development pattern.
\end{abstract}

Keywords-tourist attractions; spatial structure; optimization; Ankang.

\section{INTRODUCTION}

The spatial structure of tourist attractions is the key object and hot content of tourism spatial structure research[1-2] and has always attracted academics' attention, especially Chinese scholars. The study methods can be generally summarized as the following three kinds: First, use the fractal theory to reveal the fractal geometry of tourism attractions system spatial structure basing on fractal dimension estimates[3-4]. Second, the application of graph theory on the topology parameters are useful for quantitative analysis of tourist attractions traffic

Sponsor: National Natural Science Foundation of

China(No.41601174),Social Science Foundation of Shaanxi Province, China

(No.2015D055), The Science Foundation of Northwest

University(No.14NW03)

*Corresponding author: E-mail: ruiyang@nwu.edu.cn network structure[5-6]. Third, use GIS technology to explore the spatial distribution pattern of tourist attractions[7-8], combined with spatial statistics and mathematical statistics Due to the obvious advantages of GIS in data visualization, information mapping and the enhancement of spatial analysis ability, research results following in the third way conducted in recent years, but the analysis object focuses on the economic zone[9], city circle[10] and other tourist hotspots, or concentrated in large-scale areas such as national[8], provincial[11], regional[12], city-wide comprehensive research is rarely few[13]. There are many literatures studied on spatial structure characteristics of tourist attractions but only few probes into Optimization countermeasures of tourist attractions spatial structure.

On the basis of this, we take Shaanxi Ankang which located in the hinterland of China Qinba mountain areas as a case, explore spatial distribution characteristics, structure and pattern of its class-A tourist attractions with a combination of coefficient of variation, spatial cluster, nuclear density estimation; make suggestions on the adjustment of spatial structure system and distribution with Zipf model so that to provide scientific reference for the spatial structure optimization of Ankang tourist attractions and ideas for studies on city-wide spatial structure of tourist attractions. 


\section{DATA AND METHODOLOGY}

A. Data

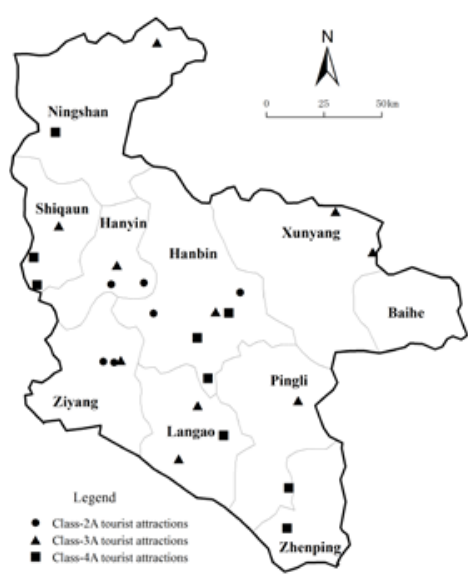

Fig. 1. Spatial distribution of Ankang class-A tourist attractions

The data are obtained from the Shaanxi Tourism Administration Web (http://www.sxta.gov.cn), Ankang Tourism Web (http://www.ankangtour.gov.cn). By the end of 2016, there're 25 national class-A tourist attractions in Ankang, of which the number of class- $4 \mathrm{~A}$ is 9 , class-3A is 10 , class- $2 \mathrm{~A}$ is 6 . With the help of Baidu map coordinate picker, we obtain the geographical coordinates of the tourist attractions and approved it by xGeocoding software. Abstract the tourist attractions as a dot-like element; we use ArcGIS10.2 software to map the spatial distribution of class-A tourist attractions in the vector map (Fig.1)

\section{B. Methodology}

1)Coefficient of variation. It can measure the relative change degree of point-feature in space and determine the distribution of tourist attractions[14]. It is defined as follows:

$$
\mathrm{CV}=\sqrt{\sum_{i=1}^{n}\left(S_{i}-\bar{S}\right) / n \bar{S}^{2}} \times 100 \%
$$

Where $S_{i}$ is the acreage of No. $i$ Voronoi polygon, $n$ is the number of Voronoi polygons; $\sqrt{\sum_{i=1}^{n}\left(S_{i}-\bar{S}\right)^{2} / n}$ is the standard deviation, $\bar{S}$ is its average.

2)Duyckaerts three-step iterative method. It is proposed by Duyckaerts et al[15], which use the Voronoi polygon area to generate a clustering point cluster by a three-step iterative method. See the relevant references for specific steps[13].

3)Nuclear density estimation. It is a method of expressing density distribution of point-features more intuitive and smooth compared with point density and line density. With the help of the movement of the search window, the plot density of the tourist attractions is smoothly collected to reflect the overall pattern of its spatial distribution. It is defined as follows[16]:

$$
f_{n}(X)=\frac{1}{n h^{2}} \sum_{i=1}^{n} k\left(X-X_{i} / h\right)
$$

Where $k\left(X-X_{i} / h\right)$ is the nuclear density equation, $\left(X-X_{i}\right)$ represents the distance from the valuation point $X$ to the tourist attraction $X_{i}, h$ is the bandwidth so as to search radius, $n$ is the total number of the tourist attractions

\section{ANALYSIS ON THE SPATIAL STRUCTURE OF TOURIST ATTRACTIONS}

\section{A. Spatial distribution characteristics of tourist attractions}

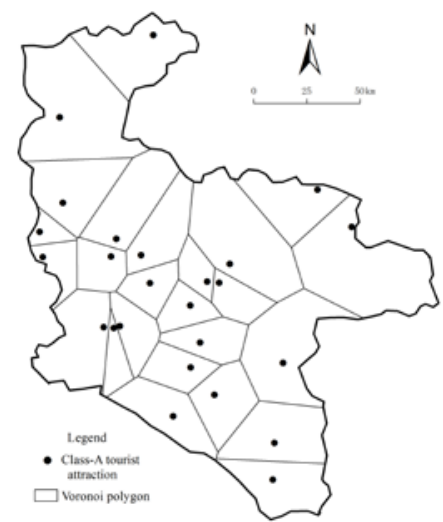

Fig. 2. Voronoi diagram of Ankang class-A tourist attractions

To identify the spatial distribution of class-A tourist attractions in Ankang, we measure the coefficient of variation (CV) of Voronoi polygon. Use ArcGIS10.2 to draw the Voronoi image of tourist attractions distribution (Fig.2). The average of 25 polygons is $898.63 \mathrm{~km} 2$, standard deviation is 561.93 , so the CV value is $159.92 \%$ which is much larger than the critical value $(64 \%)$ raised by Duyckaerts ${ }^{[15]}$. It shows that class-A tourist attractions of Ankang is clustered in space.

\section{B. Spatial distribution structure of tourist attractions}

Make further exploration on number and distribution of clustering point group of Ankang class-A tourist attractions through spatial clustering analysis. The smallest polygon of Ankang class-A tourist attractions Voronoi diagram is 0.20 million $\mathrm{km}^{2}$, the largest is 2.27 million $\mathrm{km}^{2}$, the difference between this two more than 11 times. Take the threshold as $400 \%$, that is, cluster the polygon with the neighboring one which did not exceed to 4 times as the minimum polygon area. After 5 steps of three-step-iteration with no new class came out, five clusters are produced. It can be seen from Fig.3 that agglomeration connected with each other and form a concentrated distribution area in the middle and southern of Ankang, while the four corners are scattered and only sporadic scattered. Generally speaking, the "core-edge" feature of Ankang class-A tourist attractions spatial structure is prominent. 


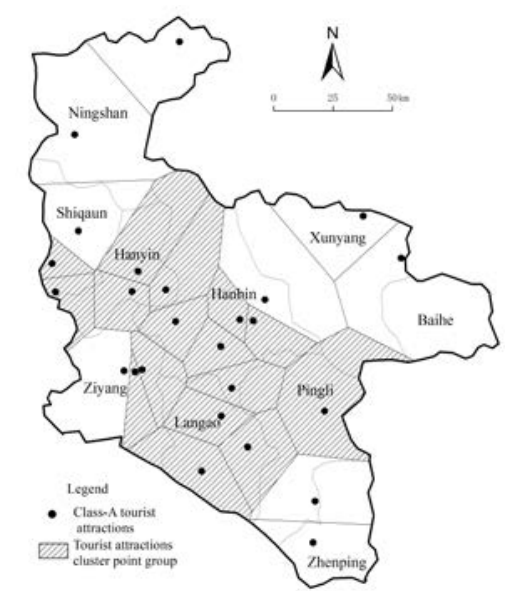

Fig. 3. Spatial clustering of Ankang class-A tourist attractions

\section{Spatial distribution pattern of tourist attractions}

Foregoing analysis has shown the distribution characteristics and structures, but still need further exploration on the specific agglomeration area and overall pattern of it. Use ArcGIS10.2 to do nuclear density mapping(Fig.4), while the bandwidth determined at $30 \mathrm{~km}$ after repeated tests. The results show that tourist attractions are mainly distributed in the Yuehe plain and along the river area of Shi-Zi-Lan, forming two agglomeration centers in the both sides of Fenghuang Mountain and central city. Compared to the Hanshui Valley, tourist attractions development and construction in Qinba middle and high mountain area is obviously lagging behind. Spatial distribution pattern of Ankang class-A tourist attractions is not only shaped by the terrain contours of "Three mountains folder Two rivers", but also influenced by "One mountain(Nangong Mountain) One lake (Yinghu) One city (Ankang central city)" local tourism practice of core tourist attractions, it also reflects the uneven development of urban tourism.

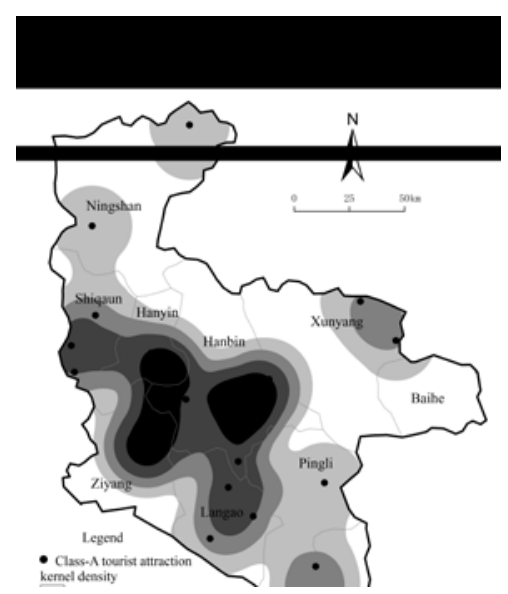

Fig. 4. Nuclear density of Ankang class-A tourist attractions

\section{SPATIAL STRUCTURE OPTIMIZATION OF TOURIST ATTRACTIONS}

\section{A. Perfecting tourist attractions system}

Take recent Ankang tourist attractions creation goals-class-3A in whole city reach to15 as reference value and with the help of Zipf model[9], we calculate near-term forecast number of 3A, 4A, 3A, 2A and 1A tourist attractions by $9,11,15,23,45$. Regarding that creation of class-5A tourist attractions request high standard, great difficulties and the declarations number is strictly controlled, Shaanxi province only aim it target at 11 in 2020, so we adjust the number of Ankang class-5A tourist attractions to 2. According to that, we make the scale system standard-step-pyramid chart of tourist attractions in recent forecast scenario (Fig.5). Compared with the actual number, we find the gap between them is relatively large, in which class $1 \mathrm{~A}, 2 \mathrm{~A}$ shows the most prominent difference. Obviously, Ankang class-A tourist attractions have not formed a stable pyramid-scale structure yet. Both the highest-level and low-level tourist attractions have shortage in development. It may affect the core tourist attractions to play their demonstration driven effect and lead to the lack of potential upgrading of tourist attractions and system development. It's necessary to take the class-5A conduction of YingHu and Nangong Mountain core tourist attractions as a break, take class-4A,3A tourist attractions conduction as key points and class-2A,1A as basement. Set quantity expansion, quality ascension, collaboration and global development together to build a reasonable system of class-A tourist attractions in Ankang.

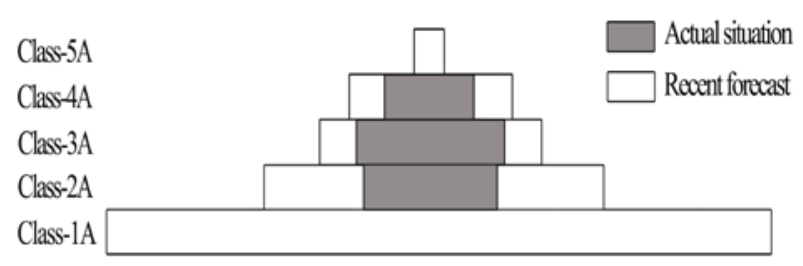

Fig. 5. Comparison of actual scale system \& recent forecast of Ankang class-A tourist attractions

\section{B. Optimization of tourist attractions pattern}

With the "Grasp the core, Strengthen the northwest, Expand the southeast" develop ideas, we adhere the concept that we should combine the lake and city as one part and keep the natural landscape characteristics. Continuously enhance the tourism-bear experience and service-distribute function of Ankang central city. Create Hanjiang scenery gallery and Qinba green corridor. Develop the heart of Qinling forest tour, top of Bashan meadow tour, Fenghuang mountain wonderland tour as a characteristics experience area. Build "One core Two corridors Three areas" tourism pattern in order to dock the conduction of Qinling human ecological tourism resort circle in Shaanxi Province and Bashan-Hanshui ecological leisure tourism experience area. Integrate the advantages of tourism resources, deepen the cooperation among tourism attractions, put tourist attractions points to spur line and develop rely on points and lines. Speed up the characteristics tourist routes construction such as 541 national road eco-tourism economic zone, Yuehe plain leisure agriculture tourism zone, "Bashan 
Gallery" tourism poverty alleviation zone and Pingli beautiful rural customs line and then let the zone to drive the whole area, boost the global tourism development.

\section{CONCLUSION}

1)Spatial clustering character of Ankang class-A tourist attractions is significant and shown a prominent "core-edge" spatial structure feature.

2)Ankang class-A tourist attractions are mainly distributed in the Yuehe plain and along the river area of Shi-Zi-Lan, Simultaneously forming two agglomeration centers in the both sides of Fenghuang Mountain and the central city. The pattern was shaped by regional topography features, practice of local tourism development and other factors in common.

3)The key to optimize the spatial structure of Ankang class-A tourist attractions lies in 2 points: First, promote the tourist attractions to set quantity expansion, quality ascension and collaboration together in order to form a reasonable system; Second, grasp the core tourist attractions, enhance the northwest area and expand the southeast area to build a "One core Two corridor Three areas" regional tourism development pattern.

\section{REFERENCE}

[1] WANG H, LI Y Z. A study on spatial structure of scenic areas in Dalian City and its optimization. Areal Research and Development, 2010, 29(1):84-89. (In Chinese)

[2] PAN J H, LI J F. Analysis on spatial structure of A-grade scenic spots in China based on quantitative geography model. Economic Geography, 2013, 33 (9):154-160. (In Chinese)

[3] XV Z H, DAI X J, ZHUANG D C, et al. A fractal study on spatial structure of tourist scenic spots systems: a case study of Nanjing. Geographical Research, 2007, 26(1):132-140. (In Chinese)
[4] CUI D S, SUN Y. A fractal-dimension-based study on optimization of spatial structure of Huzhou tourism scenic system. Scientia Geography Sinica, 2011, 31(3):337-343. (In Chinese)

[5] BIAN $X$ H. Research on spatial configuration of national grading-AAAA tourist district in the Yangtze River Delta.Economic Geography, 2007, 27(1):157-160. (In Chinese)

[6] CHENG H F, HU W H. Spatial structure of class-A tourist attraction in Chizhou.Scientia Geography Sinica, 2014, 34(10): 1275-1280. (In Chinese)

[7] ZHU H, CHEN X L. Space distribution structure of A-grade scenic spot in China. Scientia Geography Sinica, 2008, 28(5): 607-615. (In Chinese)

[8] PAN J H, LI J F. Spatial distribution characteristics and accessibility of A-grade tourist attractions in China. Journal of Natural Resources, 2014, 29(1):55-66. (In Chinese)

[9] QI X, WANG Y. Study on the spatial structures of tourist attractions in Chengyu economic zone. Geography and Geo-information Science, 2013, 29(1):105-110. (In Chinese)

[10] YUAN J, YU R L, LIU C L, et al. Research on spatial structure of national A-grade tourist districts of Wuhan metropolitan area. Economic Geography, 2010, 30(2):324-328. (In Chinese)

[11] LIU L M, LV J. Research on spatial form evolution of inbound tourism destination in Inner Mongolia. Journal of Arid Land Resources and Environment, 2016, 30(11):203-208. (In Chinese)

[12] LI W Z. Evolution and inherent mechanism of spatial structure on A-grade tourist attraction in southern Shaanxi. Research of Soil and Water Conservation, 2014, 21(5):138-143. (In Chinese)

[13] MAO X G, SONG J P, YV W. Space structure and its evolution of A-grade tourist attractions in Beijing. Economic Geography, 2011, 31(8):1381-1386. (In Chinese)

[14] XV X T, LIU D J, HU J, et al. Spatial distribution characteristic and influence factors of rural tourism destination in China-the case of national level leisure agriculture and rural tourism demonstration sites. Economic Geography, 2015, 35(9):182-188. (In Chinese)

[15] Duyckaerts C, Godefroy G. Voronoi tessellation to study the numerical density and the spatial distribution of neurons. Journal of Chemical Neuroanatomy, 2000, 20(1): 83-92.

[16] LIU C X, WANG D G. Spatial effects and development pattern of creative tourism resource: a case study of center city of Suzhou. Geographical Research, 2016, 35(5):977-991. (In Chinese) 